\title{
Extração, caracterização, prospecção por CG-EM e efeito bactericida do óleo essencial de NIM (Azadiracht indica)
}

Extraction, characterization, prospecting by GC-MS and bactericide effect of NEEM essential oil (Azadirachta indica)

Extracción, caracterización, prospección por CG-EM y efecto bactericide del aceite esencial de NEEM (Acadirachta indica)

\author{
Roana Maria de Souza Menezes \\ ORCID: https://orcid.org/0000-0001-9168-9621 \\ Instituto Federal do Sertão Pernambucano, Brasil \\ E-mail: roana.menezes@ aluno.ifsertao-pe.edu.br \\ Jayne Ribeiro de Lima \\ ORCID: https://orcid.org/0000-0001-5774-5634 \\ Instituto Federal do Sertão Pernambucano, Brasil \\ E-mail: jayne.ribeiro@aluno.ifsertao-pe.edu.br \\ Deiseele de Souza Santos \\ ORCID: https://orcid.org/0000-0002-7928-0900 \\ Instituto Federal do Sertão Pernambucano, Brasil \\ E-mail: deiseele.santos@aluno.ifsertao-pe.edu.br \\ Juliana Cantalino dos Santos \\ ORCID: https://orcid.org/0000-0002-4702-0856 \\ Instituto Federal do Sertão Pernambucano, Brasil \\ E-mail:juliana.cantalino@ifsertao-pe.edu.br \\ Arão Cardoso Viana \\ ORCID: https://orcid.org/0000-0002-5691-1511 \\ Instituto Federal do Sertão Pernambucano, Brasil \\ E-mail: arao.viana@ifsertao-pe.edu.br
}

\begin{abstract}
Resumo
Nos últimos anos, houve incentivo ao estudo de óleos essenciais, uma vez que estes apresentam em sua composição substâncias inseticidas, antifúngicas e antibacterianas. Nesse âmbito, a Azadirachta indica, popularmente conhecida como Nim, em decorrência de seus biocompostos, tornou-se de grande interesse na comunidade de desenvolvimento científico, dado que, os ingredientes ativos da planta possuem propriedades antimicrobianas e antifúngicas. Portanto, o óleo essencial foi extraído de folhas de Nim colhidas na região de Petrolina-PE, através da técnica de ultrassom e extração por infusão usando etanol e hexano. Foi analisada a atividade antimicrobiana do óleo de Nim perante Escherichia coli e Staphylococcus spp. pela técnica de difusão de discos e microrganismos mesófilos em superfície com meio Ágar Padrão para Contagem e Ágar Batata Dextrose, bem como analisou-se o teor de umidade das folhas do Nim através de estufa de secagem. Foi observado halos de inibição de até $1,1 \mathrm{~cm}$ em Escherichia coli, enquanto no Staphylococcus spp. a maior inibição foi de $8 \mathrm{~mm}$. Na inibição de microrganismos mesófilos houve uma drástica diminuição da contaminação das superfícies analisadas, onde os óleos extraídos por ambas as técnicas mostraram grande eficiência e potencial promissor para serem utilizados como método de controle. As folhas de Nim apresentaram teor de umidade de $62,32 \%$. No que se refere ao rendimento do óleo a técnica de extração por infusão foi a mais vantajosa, mas, em termos de tempo de processo, simplicidade e baixa temperatura a técnica de ultrassom se mostrou superior.
\end{abstract}

Palavras-chave: Óleo de Nim; Azadirachta indica; Escherichia coli; Staphylococcus spp; Antimicrobiano.

\begin{abstract}
In recent years, there has been an incentive to study essential oils, since these contain insecticidal, antifungal and antibacterial substances in their composition. In this context, Azadirachta indica, popularly known as Neem, due to its biocompounds, has become of great interest in the scientific development community, given that the active ingredients of the plant have antimicrobial and antifungal properties. Therefore, the essential oil was extracted from Neem leaves collected in the Petrolina-PE region, through the technique of ultrasound and extraction by infusion using ethanol and hexane. The antimicrobial activity of Neem oil against Escherichia coli and Staphylococcus spp. by the diffusion technique of discs and mesophilic microorganisms on the surface by the Pour Plate with PCA (Plate Count Agar) and Spread Plate with PDA (Potato Dextrose Agar) techniques, as well as the moisture content of Neem
\end{abstract}


leaves through a greenhouse drying. Inhibition halos of up to $1.1 \mathrm{~cm}$ were observed in Escherichia coli, while in Staphylococcus spp. the greatest inhibition was $8 \mathrm{~mm}$. In the inhibition of mesophilic microorganisms there was a drastic decrease in the contamination of the analyzed surfaces, where the oils extracted by both techniques showed great efficiency and promising potential to be used as a control method. Neem leaves had a moisture content of $62.32 \%$. With regard to oil yield, the infusion extraction technique was the most advantageous, but in terms of process time, simplicity and low temperature, the ultrasound technique proved to be superior.

Keywords: Neem oil; Azadirachta indica; Escherichia coli; Staphylococcus spp; Antimicrobial.

\section{Resumen}

En los últimos años hubo un incentivo para estudiar los aceites esenciales, ya que estos contienen sustancias insecticidas, antifúngicas y antibacterianas en su composición. En este contexto, Azadirachta indica, conocida como Neem, por sus biocompuestos, se ha vuelto de gran interés en la comunidad de desarrollo científico, dado que los principios activos de la planta tienen propiedades antimicrobianas y antifúngicas. Por lo tanto, el aceite esencial fue extraído de hojas de Neem cosechadas en la región Petrolina-PE, mediante la técnica de ultrasonido y extracción por infusión utilizando etanol y hexano. Se analizó la actividad antimicrobiana del aceite de Neem contra Escherichia coli y Staphylococcus spp. mediante la técnica de difusión de discos y microorganismos mesofílicos sobre una superficie con Agar Estándar y Agar Papa Dextrosa, así como el análisis del contenido de humedad de las hojas de Neem a través de un invernadero secador. Se observaron halos de inhibición de hasta $1,1 \mathrm{~cm}$ en Escherichia coli, mientras que en Staphylococcus spp. la mayor inhibición fue de $8 \mathrm{~mm}$. En la inhibición de microorganismos mesofílicos hubo una drástica disminución en la contaminación de las superficies analizadas, donde los aceites extraídos por ambas técnicas mostraron gran eficiencia y potencial prometedor para ser utilizados como método de control. Las hojas de neem tenían un contenido de humedad del $62,32 \%$. Con respecto al rendimiento de aceite, la técnica de extracción por infusión fue la más ventajosa, pero en términos de tiempo de proceso, simplicidad y baja temperatura, la técnica de ultrasonido demostró ser superior.

Palabras clave: Aceite de Neem; Azadirachta indica; Escherichia coli; Staphylococcus spp; Antimicrobiano.

\section{Introdução}

Nos últimos anos, houve incentivo ao estudo de subprodutos de plantas medicinais, como os óleos essenciais, uma vez que estes apresentam em sua composição substâncias inseticidas, antifúngicas e antibacterianas (Hillen et al., 2012). Nesse âmbito, a Azadirachta indica, popularmente conhecida como Nim, é uma planta pertencente a família Meliaciae, como o mogno, sendo nativa de regiões da Ásia e tendo sido introduzida no Brasil menos de 35 anos atrás (Carpanezzi; Neves, 2010).

Nesse sentido, o uso medicinal do Nim é conhecido e tem sido usado há séculos no Oriente como tratamento de diversas enfermidades, além de sua utilidade como repelente e praguicida na agricultura, uma vez que a procura por compostos naturais que apresentem potencial curativo e preventivo, sem efeitos tóxicos desfavoráveis, tem aumentado nas últimas décadas (Yacila et al., 2015). Além desses usos, Carpanezzi e Neves (2010), destacam o valor social do Nim que também deve ser reconhecido, dado que a árvore é utilizada por populações de baixa renda em climas semiáridos como produtor de madeira, e por vezes, esse valor é subestimado ou esquecido.

Nesse seguimento, o óleo do Nim é um produto que pode ser obtido a partir das sementes e amêndoas da planta e possui reconhecidos benefícios quanto ao seu uso como antibacteriano e antifúngico comprovados por diversos estudos (De et al., 2014; Susmitha et al., 2013; Kurekci et al., 2013; Serrone; Nicoletti, 2013). Sendo assim, na área da produção de alimentos o Nim se mostra como sendo vantajoso, dado que, como abordado por Serrone e Nicoletti (2013), o uso de antimicrobianos derivados de plantas na preservação de alimentos não é uma novidade e está aumentando gradativamente, justifica-se que por uma questão de fato, o uso excessivo descontrolado de antibióticos como suplementos alimentares comuns pode levar ao aumento do número de bactérias resistentes a antibióticos. Nesse contexto, a crescente incidência de doenças transmitidas por alimentos, juntamente com as implicações sociais e econômicas resultantes, causa um impulso constante para produzir alimentos, estes mais seguros e para desenvolver novos agentes antimicrobianos naturais (Palanappin \& Holley, 2011), logo, a exploração de antimicrobianos extraídos de plantas, como o Nim, mostra-se como uma maneira inovadora de encontrar substâncias alternativas aos antibióticos atualmente (Serrone \& Nicoletti, 2013). 


\section{Metodologia}

A pesquisa foi realizada no Instituto Federal do Sertão Pernambucano Campus Petrolina, utilizando os laboratórios de Química Analítica e Microbiologia. A matéria-prima utilizada para as extrações dos óleos foram as folhas da árvore Azadirachta indica, conhecida como Nim. Utilizou-se duas técnicas de extração: a extração por infusão e a extração por ultrassom. Foram realizadas análises quanto ao poder de inibição do óleo de Nim perante bactérias Gram-positivas, Gramnegativas e mesófilas e, análise quanto ao percentual de umidade das folhas.

As folhas de Nim foram colhidas em árvores da região da cidade de Petrolina-PE; sendo levadas até o laboratório de Química Analítica onde foram trituradas em um processador de alimentos. Na técnica de extração por ultrassom, pesou-se 50g da amostra triturada, sendo colocadas em Erlenmeyer e adicionado $200 \mathrm{~mL}$ de solvente (nas extrações foram usados etanol e hexano), sendo então, colocados em Agitador Magnético ficando sob agitação durante 2 horas. Em seguida, o Erlenmeyer foi transferido para o Banho de Ultrassom, com água suficiente para cobrir a amostra, em temperatura ambiente e frequência ultrassônica de $25 \mathrm{kHz}$ e potência ultrassônica de $110 \mathrm{~W}$. O processo no ultrassom levou 1 hora. Por fim, a amostra foi filtrada utilizando bomba de vácuo e papel filtro, levada para a recuperação do solvente e obtenção do óleo que foi acondicionado em frasco âmbar e refrigerado em geladeira (temperatura máxima de $5^{\circ} \mathrm{C}$ ).

Para a realização da extração por infusão, foram pesados $50 \mathrm{~g}$ da amostra, em seguida colocados em um balão de $500 \mathrm{~mL}$ e adicionados $250 \mathrm{~mL}$ de solvente (nas extrações utilizou-se etanol e hexano). Em seguida o balão foi posto no evaporador sendo aquecido por Manta Térmica com temperatura controlada variando entre $65-75^{\circ} \mathrm{C}$ durante 5 horas. Após esse período de tempo, a amostra foi filtrada utilizando uma bomba a vácuo e papel filtro, sendo transferida para um rotaevaporador para a recuperação do solvente e obtenção do óleo, sendo este guardado em frasco âmbar e levado para ser refrigerado na geladeira em temperatura máxima de até $5^{\circ} \mathrm{C}$.

As bactérias usadas foram a Escherichia coli e Staphylococcus spp.; Para a obtenção das colônias de Escherichia coli foi feita a semeadura em ágar Mueller Hinton pela técnica de estrias e incubada em estufa a $35 \pm 1^{\circ} \mathrm{C}$ por 24 horas; a mesma técnica foi aplicada para o Staphylococcus spp. que foi semeado em ágar Baird Parker e incubado em estufa a $35 \pm 1^{\circ} \mathrm{C}$ por 24 horas. Para analisar a atividade antibacteriana dos óleos de Nim, utilizou-se a técnica de difusão em disco (ANVISA, 2008), usando discos de papel filtro que foram imersos em $2 \mathrm{~mL}$ dos óleos extraídos durante 18 horas.

Tendo as placas de ágar Mueller Hinton e ágar Baird Parker com as colônias de Escherichia coli e Staphylococcus spp., respectivamente, desenvolvidas, com uma alça bacteriológica, coletou-se 2 colônias com mesmo tipo morfológico de cada placa e foram inoculadas em tubos de $10 \mathrm{~mL}$ de solução salina a $0,85 \%$, essa quantidade de colônias mostrou-se suficiente para obter a turvação semelhante ao tubo 0,5 da escala de Mac Farland (concentração aproximada de $10^{8} \mathrm{microrganismos} / \mathrm{mL}$ ), em seguida foram imersos swabs estéreis na suspensão bacteriana de Escherichia coli e Staphylococcus spp., retirado o excesso de líquido, comprimindo-o contra a parede do tubo, e semeado suavemente, em todos os sentidos, na superfície de placas com ágar Mueller Hinton. As placas foram separadas em 3 quadrantes, onde, em cada um deles foi adicionado 1 disco de papel filtro que estava imerso no óleo de Nim. Cada microrganismo recebeu 1 placa contendo discos imersos em óleo de Nim extraído por ultrassom com hexano, 1 placa por ultrassom com etanol, 1 placa por extração por infusão com hexano e 1 placa por extração por infusão com etanol. Após esse processo, as placas foram incubadas em estufa sem inverter por $18 \mathrm{~h}$ à $35 \pm 1^{\circ} \mathrm{C}$. Em seguida, os halos de inibição foram medidos com auxílio de uma régua.

Para a realização da análise de bactérias mesófilas (Brasil, 2003), fez-se a coleta da contaminação da superfície de um banheiro de funcionários de um estabelecimento comercial. Fez a definição da região a ser testada usando um delimitador de área, utilizando swab estéril fez-se a coleta da contaminação da região, sendo então inoculado em tubo contendo 10 mL de água peptonada $0,1 \%$. Em seguida, fez-se a delimitação de mais uma região do mesmo local, onde, aplicou-se $2 \mathrm{~mL}$ do óleo de Nim, deixando agir durante 5 minutos, sendo após esse tempo, coletado a amostra da região com swab e inoculada em tubo de 
$10 \mathrm{~mL}$ de água peptonada $0,1 \%$; esse procedimento foi realizado com todos os óleos de Nim extraídos: óleo de Nim extraído com etanol e hexano por Ultrassom e o óleo extraído com etanol e hexano pela extração por infusão seguida de rotaevaporação. Após a coleta, as amostras foram levadas ao laboratório de Microbiologia. Retirou-se $1 \mathrm{~mL}$ de cada tubo de água peptonada $0,1 \%$ e inoculou-se em placas de Petri estéreis, tendo-se separado uma placa para cada amostra de óleo, em seguida, fazendo uso da técnica de plaqueamento Pour Plate, verteu-se o meio de cultivo PCA (Plate Count Agar), fundido e homogeneizou 5 vezes para a direita, 5 vezes para a esquerda e 5 vezes em formato de oito. Após a solidificação do meio, as placas foram invertidas e incubadas em estufa a $35 \pm 1^{\circ} \mathrm{C}$ por até 48 horas. Também retirou-se $0,1 \mathrm{~mL}$ da amostra cada tubo e fez-se o plaqueamento pela técnica Spread Plate em placas contendo PDA (Potato Dextrose Agar) solidificado acidificado com ácido tartárico $10 \%$, que sem seguida foram espalhadas com auxílio de uma alça de Drigalski. Em seguida, as placas foram incubadas em estufa sem inverter a $25^{\circ} \mathrm{C}$ por até 5 dias. Os resultados foram expressos em UFC (Unidade Formadora de Colônia)/ $\mathrm{cm}^{2}$ conforme os padrões internacionais da Organização Panamericana de Saúde (OPAS) e Organização Mundial da Saúde (OMS).

O perfil cromatográfico foi feito através de cromatografia gasosa. As análises foram realizadas utilizando um Cromatógrafo de gás, Agilent Technologies modelo 7820A GC system acoplado a um detector seletivo de massas, Agilent Technologies modelo 5977E MSD). A aquisição e processamento dos dados foi por meio do Software MassHunter Agilent Technologies TM (Santa Clara, CA, USA). Foi usado o modo Split com relação de 30:1 e divisão de fluxo de $15 \mathrm{~mL} / \mathrm{min}$ a 200 $\mathrm{oC}$ no injetor. A coluna empregada foi a Capillary Column CP-WAX $52 \mathrm{CB}(30 \mathrm{~m}$ x $0.25 \mathrm{~mm}$ x $0.25 \mu \mathrm{m})$ (Varian, Lake Forest, CA, USA), com fluxo de $0,5 \mathrm{~mL} / \mathrm{min}$. A temperatura do forno foi de $60^{\circ} \mathrm{C}(1 \mathrm{~min})$, aquecimento de $10^{\circ} \mathrm{C} / \mathrm{min}$. Até $200^{\circ} \mathrm{C}(5$ min.) e temperatura máxima do forno em $220^{\circ} \mathrm{C}$, com tempo total da corrida de $20 \mathrm{~min}$. A temperatura do detector foi controlada em $200^{\circ} \mathrm{C}$ e a fase móvel utilizada foi o gás Hélio com grau de pureza 6.0. As corridas foram realizadas no modo SCAN, verificando os tempos de retenção e íons específicos para os padrões utilizados. A identificação das moléculas foi complementada através da comparação dos resultados com a biblioteca de espectro Instituto Nacional de Padrões e Tecnologias (NIST). Foram realizadas injeções com a técnica de injeção líquida para avaliação das amostras.

$\mathrm{Na}$ análise do teor de umidade das folhas do Nim, foram utilizados 3 cadinhos de porcelana que foram enumerados a lápis e postos em estufa de secagem a $105^{\circ} \mathrm{C}$ por 30 minutos, sendo em seguida levados a dessecador para esfriar, pesados e tarados em balança analítica, para então, pesar $5 \mathrm{~g}$ das folhas de Nim in natura maceradas e anotados os pesos de cadinho + amostra. Seguidamente, os cadinhos com as amostras foram lavados para a estufa a $105^{\circ} \mathrm{C}$ por 3 horas. Posteriormente, os cadinhos foram retirados e colocados no dessecador para esfriar por 30 minutos, pesados e tendo os pesos anotados e levados a estufa por mais 1 hora, onde, logo após, foram retirados e levados ao dessecador por 15 minutos, pesados e retornados a estufa por mais 1 hora. As pesagens e incubação na estufa de secagem se seguiram até que os cadinhos atingissem peso constante.

\section{Resultados e Discussão}

\subsection{Análise da atividade antimicrobiana do óleo de folhas de Nim}

Os resultados da análise de difusão de discos para se saber o poder de inibição do óleo de folhas Nim extraído com etanol e hexano pela técnica de ultrassom, podem ser visualizados na Tabela 1. 
Tabela 1 - medição dos halos de inibição de discos contendo óleo de Nim extraídos através da técnica de ultrassom e utilizando etanol e hexano como solventes em Escherichia coli e Staphylococcus spp.

\begin{tabular}{cc}
\hline Escherichia coli - óleo de Nim (solvente etanol) & Escherichia coli - óleo de Nim (solvente hexano) \\
\hline $\mathrm{a}-\mathrm{x}^{*}$ & $\mathrm{a}-\mathrm{x}$ \\
$\mathrm{b}-1 \mathrm{~cm}$ & $\mathrm{~b}-\mathrm{x}$ \\
$\mathrm{c}-1,1 \mathrm{~cm}$ & $\mathrm{c}-\mathrm{x}$ \\
\hline Staphylococcus spp. - óleo de Nim (solvente etanol) & Staphylococcus spp.- óleo de Nim (solvente hexano) \\
\hline $\mathrm{a}-7 \mathrm{~mm}$ & $\mathrm{a}-7 \mathrm{~mm}$ \\
$\mathrm{~b}-\mathrm{x}$ & $\mathrm{b}-\mathrm{x}$ \\
$\mathrm{c}-5 \mathrm{~mm}$ & $\mathrm{c}-\mathrm{x}$ \\
\hline
\end{tabular}

$\mathrm{x}^{*}=$ sem halo de inibição. Fonte: Autores.

Como é possível observar, a Escherichia coli foi a bactéria com a maior sensibilidade ao óleo de Nim extraído com etanol no ultrassom (Figura 1), sendo seguida do Staphylococcus spp. (Figura 2), dados semelhantes foram encontrados por Haider et al. (2018), que perceberam inibição do desenvolvimento de ambas as bactérias ao serem tratadas com o óleo de Nim, os autores sugerem que a hidrofobicidade parcial dos compostos fenólicos, permite com que eles se conectem à membrana externa das bactérias e alterem a fluidez da parede da membrana plasmática. A parede da membrana é então penetrada com compostos fenólicos menores que entram na membrana celular e interrompem o metabolismo. Além da possibilidade do óleo reduzir a respiração microbiana e aumentar a permeabilidade da membrana plasmática, o que resulta na perda de células bacteriana após vazamento massivo de íons.

Figura 1 - halos de inibição em E. coli sob discos de óleo de Nim extraídos com etanol por ultrassom.

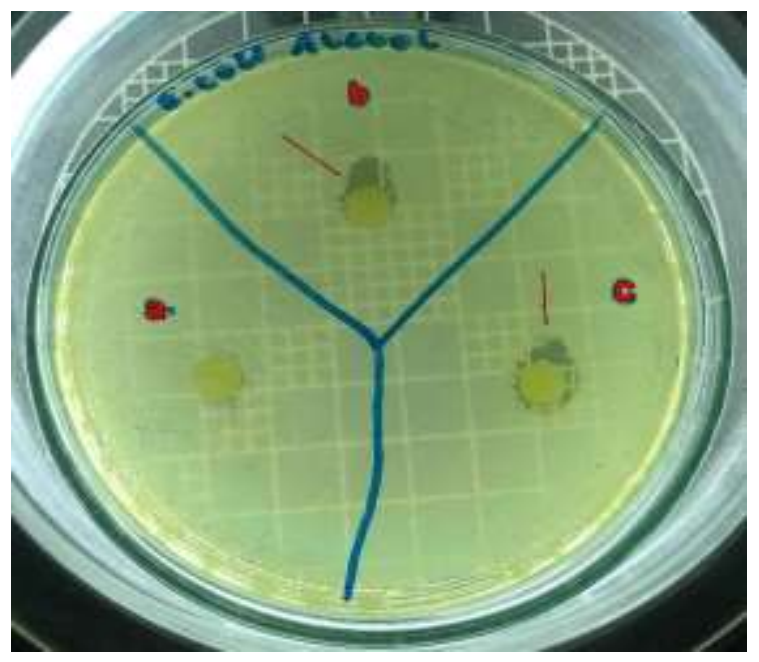

Fonte: Autores (2021). 
Figura 2 - halos de inibição em Staphylococcus spp. sob discos de óleo de Nim extraídos com etanol por ultrassom (autores, 2021).

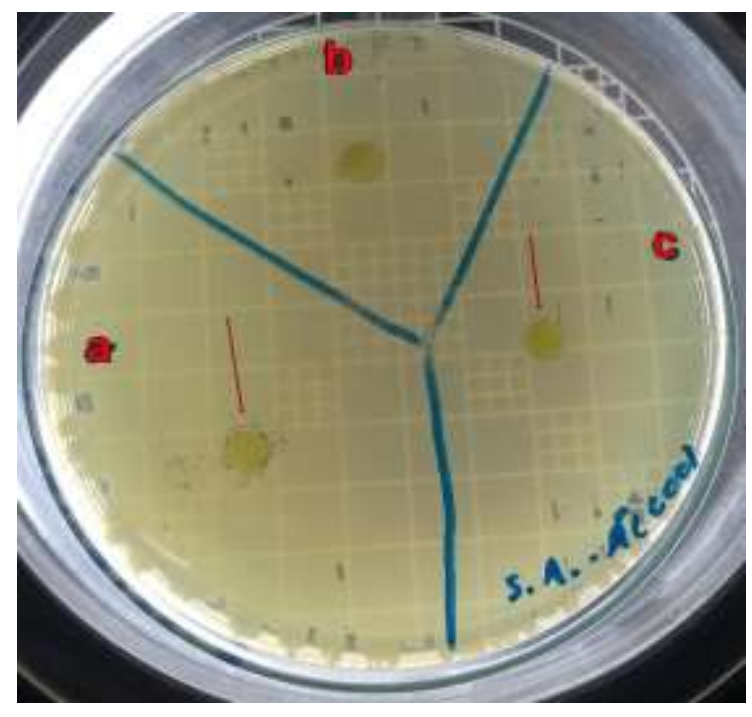

Fonte: Autores (2021).

Conforme apontado por Gosh et al. (2016), os compostos hidrofóbicos do óleo de Nim se fundem com os componentes lipídicos das paredes celulares das bactérias, assim, danificando estas e causando vazamento de componentes intracelulares. Uma vez que a camada de lipopolissacarídeos de bactérias Gram-negativas pode vir a ser uma barreira contra qualquer entrada de biomolécula, a ausência dela em bactérias Gram-positivas, como o Staphylococcus spp., faz com que a atividade antimicrobiana do óleo seja facilitada (Haider et al., 2018). Segundo Koona e Budida (2011), a atividade antibacteriana do óleo de folhas de Nim pode ser devido à presença de diferentes constituintes bioativos, como carotenóides, compostos fenólicos, flavonóides, triterpenóides, cetonas, glicosídeos, esteróides e tetra-triterpenóides azadiractina nas folhas de Azadirachta indica. Ao passo que esses são os principais compostos antibióticos da planta do Nim, usados como mecanismo de defesa contra diferentes patógenos (Kumar et al., 2020).

Asif (2012), igualmente avaliou e comprovou graus de capacidade antimicrobiana do óleo de Nim em bactérias patogênicas, entre elas a Escherichia coli e Staphylococcus spp., o autor afirma que o nível de atividade antimicrobiana do óleo de A. indica pode depender dos teores de proteína e carboidrato. Geralmente, os altos teores desses compostos no extrato apresentam melhores atividades antimicrobianas. Outros autores também comprovaram a eficiência da atividade antibacteriana do óleo de Nim extraído com etanol por ultrassom perante Staphylococcus spp. e E. coli (Fuentes \& Silva, 2013; Thiyagu E Rajeswari, 2019; Akhter \& Sarker, 2019; Hari, 2019; Kumar et al., 2020; Oyekanmi et al., 2021; SÁ et al., 2021). Não obstante, o uso do ultrassom na extração pode produzir um óleo essencial de boa qualidade sem gerar efeitos adversos na composição química e atividade antibacteriana (Hashemi et al., 2018).

Nesse âmbito, a placa contendo E. coli com óleo de Nim extraído com hexano pelo ultrassom não apresentou inibição, é possível que o hexano por si só não tenha sido eficiente na extração de quantidades relevantes dos compostos inibitórios do Nim, bem como, existe a possibilidade da potencial formação de radicais livres durante a sonólise do solvente que podem degradar alguns compostos por oxidação, uma vez que essa é a principal desvantagem da técnica de ultrassom (Mejri et al., 2018). Já na placa de Staphylococcus spp. (Figura 3), houve uma inibição de $7 \mathrm{~mm}$ no quadrante "a”, que pode ter ocorrido em decorrência das bactérias Gram-positivas poderem ser mais sensíveis a quantidades menores dos compostos contidos no óleo, assim como, existe a possibilidade da agitação da amostra não ter sido eficiente, uma vez que essa é importante para melhorar 
a transferência entre as fases imiscíveis (Haider et al., 2018) e quebrar a estrutura das folhas facilitando a extração dos compostos.

Figura 3 - placa de Staphylococcus spp. com discos de óleo de Nim extraídos com hexano por ultrassom.

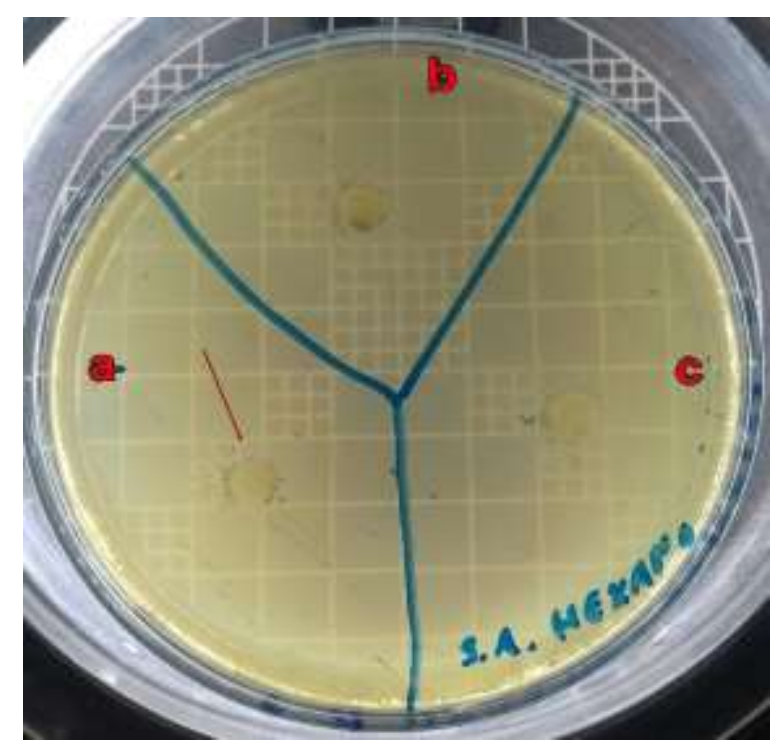

Fonte: Autores (2021).

Os resultados da análise de difusão de discos para conhecer o poder de inibição do óleo de Nim extraído com etanol e hexano pela técnica de extração por infusão seguida de rotaevaporação, podem ser visualizados na Tabela 2.

Tabela 2 - medição dos halos de inibição de discos contendo óleo de Nim extraídos através da técnica de extração por infusão e utilizando etanol e hexano como solventes em Escherichia coli e Staphylococcus spp.

\begin{tabular}{cc}
\hline Escherichia coli - óleo de Nim (solvente etanol) & Escherichia coli - óleo de Nim (solvente hexano) \\
\hline $\mathrm{a}-\mathrm{x}^{*}$ & $\mathrm{a}-\mathrm{x}$ \\
$\mathrm{b}-6 \mathrm{~mm}$ & $\mathrm{~b}-\mathrm{x}$ \\
$\mathrm{c}-\mathrm{x}$ & $\mathrm{c}-\mathrm{x}$ \\
\hline Staphylococcus spp. - óleo de Nim (solvente etanol) & Staphylococcus spp.- óleo de Nim (solvente hexano) \\
\hline $\mathrm{a}-\mathrm{x}$ & $\mathrm{a}-8 \mathrm{~mm}$ \\
$\mathrm{~b}-\mathrm{x}$ & $\mathrm{b}-5 \mathrm{~mm}$ \\
$\mathrm{c}-\mathrm{x}$ & $\mathrm{c}-7,5 \mathrm{~mm}$ \\
\hline
\end{tabular}

$\mathrm{x}^{*}=$ sem halo de inibição. Fonte: Autores (2021).

Como pode-se observar, em Escherichia coli com óleo de Nim extraído com etanol (Figura 4) houve um pequeno halo de inibição de 6 mm, já na placa de Staphylococcus spp. também com o óleo extraído com etanol não houve inibição. Dentre as possíveis causas, está a temperatura mais elevada do processo de extração, uma vez que altas temperaturas podem causar alterações químicas nos compostos dos óleos essenciais e perdas dos compostos voláteis (Mejri et al., 2018).

Estudos sugerem que com o aumento da temperatura, há o favorecimento do aumento do rendimento do óleo, este fenômeno é devido ao fato de que os óleos são geralmente mais solúveis em temperaturas elevadas, porém, a qualidade do óleo diminui conforme o calor aumenta (Tesfaye et al, 2018; Bhuyan, Sen, Bihari, 2019). 
Figura 4 - placa de E. coli com discos de óleo de Nim extraídos com etanol por extração por infusão.

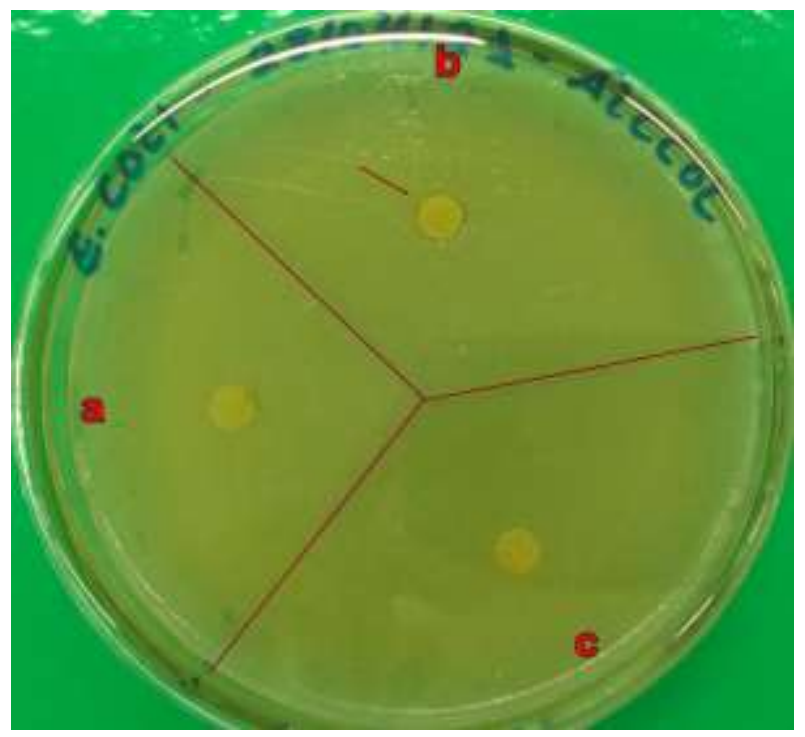

Fonte: Autores (2021).

Na difusão de discos com óleo de Nim extraído com hexano, em Escherichia coli não houve inibição, novamente, a temperatura de processo pode ter sido responsável pela degradação de quantidades consideráveis de compostos necessários para a atividade antimicrobiana do óleo. Não obstante, no que se refere a Staphylococcus spp. (Figura 5), houveram halos de inibição de $8 \mathrm{~mm}, 5 \mathrm{~mm}$ e 7,5 mm nos quadrantes "a", "b" e "c" respectivamente, possivelmente as quantidades de compostos inibitórios restantes no óleo após sua extração foram suficientes para causar efeito bactericida no microrganismo (HAIDER et al., 2018).

Figura 5 - placa de Staphylococcus spp. com discos de óleo de Nim extraídos com hexano por extração por infusão (autores, 2021).

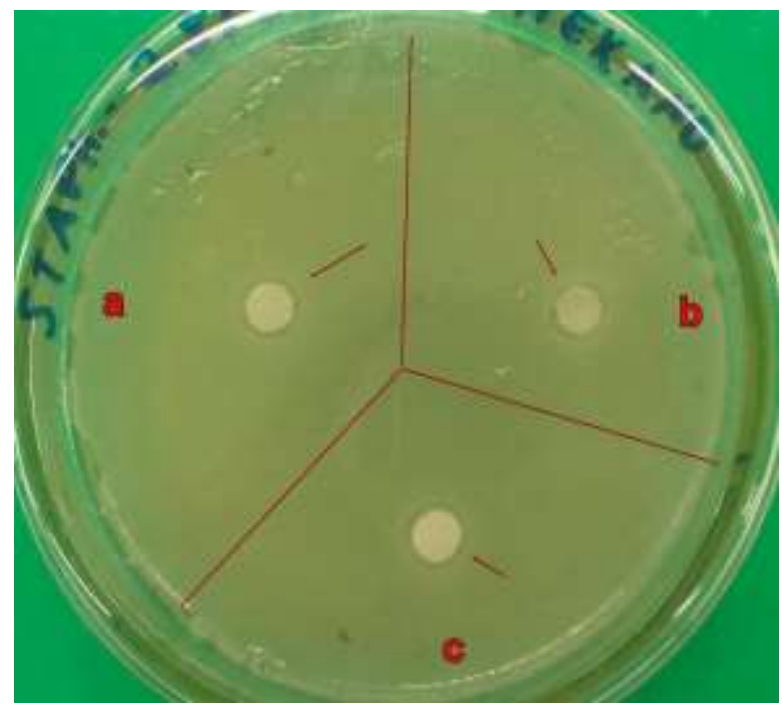

Fonte: Autores (2021).

\subsection{Rendimento dos óleos de Nim extraídos pelas técnicas de ultrassom e extração por infusão}

No que se refere ao rendimento dos óleos de Nim, extraídos com etanol e hexano pelo ultrassom, os valores podem ser vistos na Tabela 3. 
Tabela 3 - Rendimento do óleo de folhas de Nim extraído com etanol e hexano pela técnica de ultrassom.

Rendimento do óleo de Nim - extração por ultrassom

\section{Solvente etanol}

$50 \mathrm{~g}=25 \mathrm{~mL}$
Solvente hexano

$50 \mathrm{~g}=15 \mathrm{~mL}$

Fonte: Autores (2021).

Nesse sentido, o rendimento dos óleos de Nim extraídos com etanol e hexano através da extração por infusão pode ser visto na Tabela 4.

Tabela 4 - Rendimento do óleo de folhas de Nim extraído com etanol e hexano pela técnica de extração por infusão.

Rendimento do óleo de Nim - extração por infusão

\begin{tabular}{c|c}
\hline Solvente etanol & Solvente hexano \\
\hline $50 \mathrm{~g}=40 \mathrm{~mL}$ & $50 \mathrm{~g}=20 \mathrm{~mL}$ \\
\hline
\end{tabular}

Fonte: Autores (2021).

Sendo assim, a técnica de extração por infusão foi a que apresentou o maior rendimento de óleo em comparação ao ultrassom. Dentre os fatores, estão o solvente, onde o rendimento depende de qual for utilizado e aumenta com a polaridade deste (Mejri et al., 2018), bem como a temperatura de processo, quanto mais alta, mais óleo pode ser obtido (Bhuyan, Sen, Bihari, 2019).

\subsection{Análise do poder de inibição do óleo de folhas de Nim em contaminação de superfícies por microrganismos mesófilos}

Os resultados da análise da atividade de inibição de contaminação ambiente de superfície dos óleos de folhas de Nim, pela contagem de bactérias em PCA podem ser vistos na Tabela 5.

Tabela 5 - avaliação do poder inibitório do óleo de folhas de Nim extraídos com etanol e hexano pelas técnicas de ultrassom e extração por infusão em contaminação ambiente de superfície.

Contaminação de superfície - contagem em PCA (Contaminação: 90 UFC/cm²)

\begin{tabular}{cc}
\hline Etanol ultrassom: 0* & Hexano ultrassom: 3 UFC \\
\hline Etanol extração por infusão: 0 & Hexano extração por infusão: 1 UFC \\
\hline
\end{tabular}

$0^{*}=$ não houve crescimento de colônia. Fonte: Autores (2021).

Após a conclusão das análises e tendo em vista a ausência de padrões nacionais para os parâmetros de contaminação de microrganismos mesófilos em superfícies (Espich, 2014), foram considerados os padrões internacionais da Organização Panamericana de Saúde (OPAS) e Organização Mundial da Saúde (OMS) sendo 50 UFC/cm² para ambos. Atentando para esse valor, percebe-se que a contagem de $90 \mathrm{UFC} / \mathrm{cm}^{2}$ do ambiente avaliado estava acima do parâmetro máximo estabelecido, indicando uma alta carga microbiológica. No entanto, após as superfícies serem tratadas com os extratos do óleo de Nim, 
houve uma drástica diminuição da contagem, onde os locais em contato com os óleos extraídos com etanol tanto pelo ultrassom quanto pela extração por infusão não apresentaram desenvolvimento microbiológico. As superfícies tratadas com os extratos do Nim extraídos com hexano por ambas as técnicas exibiram crescimento de 3 UFC (Unidade Formadora de Colônia) do ultrassom e 1 UFC da extração por infusão. Porém, levando em consideração a alta contagem inicial, ainda houve uma inibição consideravelmente eficiente.

No que se refere a avaliação dos microrganismos mesófilos analisados através da técnica de plaqueamento por superfície com PDA, este acidificado, se tornando seletivo para o desenvolvimento de bolores e leveduras, os resultados podem ser vistos na Tabela 6.

Tabela 6 - avaliação do poder inibitório do óleo de folhas de Nim extraídos com etanol e hexano pelas técnicas de ultrassom e extração por infusão em contaminação ambiente de superfície.

\begin{tabular}{cc}
\hline \multicolumn{2}{c}{ Contaminação de superfície - contagem em PDA $($ Contaminação: 35 UFC/cm²) } \\
\hline Etanol ultrassom: 3 UFC & Hexano ultrassom: $0^{*}$ \\
\hline Etanol extração por infusão: 0 & Hexano extração por infusão: 3 UFC \\
\hline $0^{*}=$ não houve crescimento de colônia. Fonte: Autores (2021).
\end{tabular}

Levando em consideração o valor de $50 \mathrm{UFC} / \mathrm{cm}^{2}$ padronizado pela OMS e OPAS, pode-se dizer que a contaminação encontrada no ambiente de $35 \mathrm{UFC} / \mathrm{cm}^{2}$ está dentro dos parâmetros estabelecidos. Não obstante, foi possível observar que a região tratada com o óleo extraído com etanol pelo ultrassom apresentou uma atividade inibitória significativa uma vez que foram contadas apenas 3 UFC, porém, o local tratado com o óleo extraído com etanol pela extração por infusão apresentou resultado ainda mais relevante, ao passo que não houve crescimento de colônias. Em relação ao local tratado com óleo de Nim extraído com hexano por ultrassom, não houve desenvolvimento microbiano enquanto que no local em contato com o óleo de Nim com hexano extraído pela técnica de infusão, apresentou a contagem de 3 UFC.

Nesse âmbito, as regiões tratadas com os óleos extraídos pelo ultrassom que ainda apresentaram crescimento microbiológico, mesmo que mínimo, podem ser em decorrência tanto da carga destes, onde, nesta, poderiam haver microrganismos menos sensíveis aos compostos presentes nos óleos, quanto da eficiência da agitação prévia das amostras antes da extração (Haider et al., 2018). Não obstante, os locais que entraram em contato com os óleos extraídos pela extração por infusão que apresentaram desenvolvimento microbiano, podem, além da possível presença de microrganismos com menos sensibilidade aos compostos, existir a possibilidade que devido a temperatura do processo de obtenção dos óleos, estes terem alguns de seus compostos inibitórios degradados (Tesfaye et al, 2018). No entanto, com base nos dados obtidos, os óleos de folhas de Nim extraídos com etanol e hexano pelas técnicas de ultrassom e infusão, tem grande potencial para serem utilizados como método de controle de contaminação ambiental em superfícies por microrganismos mesófilos.

\subsection{Perfil cromatográfico do óleo de Nim}

Na Tabela 7, é possível observar as substâncias encontradas no óleo de Nim através de cromatografia gasosa. 
Tabela 7 - substâncias do óleo de Nim através de perfil cromatográfico.

\begin{tabular}{ccc}
\hline Substância & $\operatorname{Tr}(\mathrm{min})$ & Probabilidade (\%) \\
\hline Etilbenzeno & 3,51 & 61,6 \\
Benzeno, 1,3-dimetil & 3,57 & 40,1 \\
Benzeno, 1,3-dimetil & 4,02 & 31,1 \\
Éter, 3-butenil propil & 4,68 & 24,9 \\
Hidroperóxido, 1-etilbutila & 5,2 & 75 \\
Hidroperóxido, 1-metilpentil & 5,5 & 44,2 \\
3-metilpenta-1,4-dieno-3-ol & 5,83 & 37,4 \\
3-metilpenta-1,4-dieno-3-ol & 5,9 & 37,4 \\
\hline
\end{tabular}

Fonte: Autores (2021).

Dentre as substâncias encontradas no óleo de Nim, pode-se observar entre elas algumas com potencial antimicrobiano, como os hidrocarbonetos aromáticos etilbenzeno e benzeno, 1,3-dimetil, que em decorrência da comprovada toxicidade de ambos (Oliveira, 2013; Costa, 2011; Araújo, 2010), podem ter ação inibitória nos microrganismos alvo. No que se refere aos derivados dos hidroperóxidos encontrados, estes são componentes formados na fase inicial da autoxidação, e uma vez que eles são absorvidos, passam a ser uma potencial fonte de radicais livres o que pode causar efeitos danosos em organismos vivos (Angeli, 2011; Aditivos \& Ingredientes, 2010).

Nesse âmbito, em alguns casos, a atividade antimicrobiana do óleo essencial é em decorrência do sinergismo de diferentes classes de compostos encontrados em sua composição, como álcoois, ésteres e hidrocarbonetos (Bassolé; Juliani, 2012; Rault; Karuppayil, 2014).

\subsection{Análise do teor de umidade das folhas de Nim}

A análise do teor de umidade, como descreve Siqueira (2021), é utilizada para quantificar a água presente em uma determinada amostra. Tendo isso em vista, o teor de umidade obtido após a análise das folhas de Nim foi de 62,32\%, resultado que corrobora com o encontrado por Parckert et al. (2017) ao analisarem folhas de Nim in natura, bem como com Evbuomwan, Felix, Opute (2015). Conforme explicam Argyropoulos e Müller (2014), o teor de umidade de uma amostra pode ter influência no rendimento e extração de óleo essencial, os autores destacam que como o componente mais abundante no teor de umidade é a água, essas moléculas de água nos substratos afetarão o desempenho de extração e o rendimento. Se o valor do teor de umidade for muito alto, as moléculas de água bloquearão os poros dos substratos e interferirão no vapor para elevar o componente de óleo. Caso contrário, se o valor do teor de umidade for muito baixo, os substratos ficarão muito secos e haverá uma grande perda no número de óleo essencial dentro dos substratos.

\section{Conclusão}

Com base em todos os resultados obtidos na pesquisa, pode-se afirmar que o óleo de folhas de Nim extraído através de etanol e hexano e pelas técnicas de ultrassom e extração por infusão apresentou um potencial inibitório eficiente perante bactérias patogênicas. Em relação a técnica, o ultrassom se mostrou superior como método de extração, uma vez que reduz o tempo para realizá-la, é um equipamento simples, além de usar temperaturas amenas. Não obstante, como um método de controle de contaminação de ambiente por microrganismos mesófilos, o óleo de Nim apresenta um potencial promissor e mais estudos com foco nessa área devem ser feitos. 
Diante dos resultados obtidos, futuros trabalhos que visem a aplicação das substâncias obtidas para realização de processos de higienização na indústria de alimentos são sugeridos, buscando criar mais uma alternativa sustentável para os processos de sanitização.

\section{Agradecimentos}

Os autores agradecem ao IFSertãoPE e ao CNPQ pelo fornecimento de bolsa, para realização do projeto PIBIC/CNPQ.

\section{Referências}

Aditivos \& Ingredientes. (2010). A Rancidez Oxidativa em Alimentos. Recuperado de: http://www.insumos.com.br/aditivos_e_ingredientes/materias/209.pdf

Angeli, J. P. F. (2011). Hidroperóxidos de lipídios como fontes de oxigênio molecular singlete $\left(\mathrm{O}_{2}\left[{ }^{1} \Delta_{\mathrm{g}}\right]\right)$, detecção e danos em biomoléculas. (Tese de Doutorado). Universidade de São Paulo, São Paulo.

Akhter, R., \& Sarker, W. (2019). Antimicrobial activity in leaf extract of neem in broiler. Res. Agric. Livest. Fish., 6 (2), 337-343.

Alzohairy, M. A. (2016). Therapeutics Role of Azadirachta indica (Neem) and Their Active Constituents in Diseases Prevention and Treatment. EvidenceBased Complementary and Alternative Medicine, 1, 1-11.

Anvisa. (2008). Técnicas para avaliação da sensibilidade aos antimicrobianos. Agencia Nacional de Vigilancia Sanitária - ANVISA c2008. Recuperado de https://www.anvisa.gov.br/servicosaude/controle/rede_rm/cursos/boas_praticas/modulo5/interpretacao2.htm

Araújo, K. C. N. (2010). Degradação de hidrocarbonetos por fungos filamentosos. (Monografia de Especialização), Instituto de Ciências Biológicas da Universidade Federal de Minas Gerais, Belo Horizonte.

Argyropoulos, D., \& Muller, J. (2014). Changes of essential oil content and composition during convective drying of lemon balm (Melissa officinalis L.). Industrial Crops and Products, 52, 118-124.

Asif, M. (2012). Antimicrobial Potential of Azadirachta indica Against Pathogenic Bacteria and Fungi. Journal of Pharmacognosy and Phytochemistry, 1(4), 78-83.

Bassolé, I., \& Juliani, H. (2012). Essential Oils in Combinationand Their Antimicrobial Properties. Molecules, 17, 3989-4006.

Bhuiya, M. M. K., Rasul, M. G., Khan, M. M. K., Ashwath, N., \& Azad, A. K. (2016). Prospects of 2nd generation biodiesel as a sustainable fuel—Part: 1 selection of feedstocks, oil extraction techniques and conversion technologies. Renewable and Sustainable Energy Reviews, 55, 1109-1128.

Brasil. ANVISA. RDC (2), de (2007). Diário Oficial da União.

Bhuyan, P., Sen, S., \& Bihari, V. Extraction of Neem (Azadirachta Indica) oil using blends of hexane, ethyl acetate and acetone by sonication. International Journal of Advance Research, Ideas and Innovations in Technology, 5(2), 78-84, 2019.

Biasi, L. A, Deschamps, C. (2008). Plantas aromáticas: do cultivo à produção de óleo essencial. Curitiba: Layer Studio Gráfico e Editora Ltda.

Bittante, A. M. Q. B., Bovo, F., \& Oliveira, C. A. F. (2012). Aplicação de compostos antimicrobianos naturais em biofilmes para embalagens de alimentos. Higiene Alimentar, 26(214/215), 102-109.

Boone, C. V. (2011). Estudo químico do óleo essencial das raízes de Piper amalago. (Trabalho de Conclusão de Curso), Universidade Estadual de Mato Grosso do Sul, Dourados.

Brasil, R. B. (2010). Estudo fitoquímico e Atividade Fungicida do Extrato Metanólico das Folhas de Azadirachta indica (A. Jusseu). (Dissertação de Mestrado) Universidade Federal do Pará, Belém.

Brasil, R. B. (2013). Aspectos botânicos, usos tradicionais e potencialidades de Azadirachta indica (Neem). Enciclopédia Biosfera, Centro Científico Conhecer,9(17), 3252.

Brasil. Instrução Normativa ${ }^{\circ} 62$ de 26 de agosto de 2003. Oficializa os métodos analíticos oficiais para análises microbiológicas para controle de produtos de origem animal e água. Brasília, DF. Diário Oficial da União. Brasília, DF.

Busato, N. V., Silveira, J. C., Costa, A. O. S., \& Costa Junior, E. F. (2014). Estratégias de modelagem da extração de óleos essenciais por hidrodestilação e destilação a vapor. Ciência Rural, 44(9), 1574-1582.

Carpanezzi, A. A.; \& Neves, E. J. M. (2010). Balanço dos aspectos técnicos do cultivo do nim no Brasil. Colombo: Embrapa Florestas.

Chemat, F., Rombault, N., Sicaire, A. G., Meullemiestre, A., Fabiano-Tixier, A. S., \& Albert-Vian, M. (2017). Ultrasound assisted extraction of food and natural products. Mechanisms, techniques, combinations, protocols and applications. A review. Ultrasonics Sonochemistry, 34, 540-560.

Chemat, F., Zill-E-Huma, \& Khan, M. K. (2011). Applications of ultrasound in food technology: Processing, preservation and extraction. Ultrasonics Sonochemistry, 18, 813-835. 
Costa, A. S. (2011). Emprego de turfa e resíduo de angico branco (Anadenanthera colubrina) na remediação de btex em água produzida. (Dissertação de Mestrado) Universidade Federal de Sergipe, São Cristóvão.

Dai, J., Orsat, V., Raghavan, G.S., \& Yaylayan, V. (2010). Investigation of various factors for the extraction of peppermint (Mentha piperitaL.) leaves. Journal of Food Engineering, 96, 540-543.

Danh, L. T., Triet, N. D. A., Han, L. T. N., Zhao, J., Mammucari, R., \& Foster, N. (2012). Antioxidant activity, yield and chemical composition of lavender essential oil extracted by supercritical CO2. The Journal of Supercritical Fluids, 70, 27-34.

De, B., Gupta, K., Mandal, M., \& Karak, N. (2014). Tough hyperbranched epoxy/neem-oil-modified OMMT thermosetting nanocomposite with an antimicrobial atribute. Royal Society of Chemistry, Montpellier.

D, G. C., Maheshwarib, R.C., \& Naika, S.N. (2011). Extraction of natural insecticide azadirachtin from neem (Azadirachtaindica A. Juss) seed kernels using pressurized hot solvent. The Journal of Supercritical Fluids, 56, 253-258.

Diedhiou, M. D. (2017). Fractionnement analytique de la graine de neem (Azadirachta indica A.Juss.) et de la graine de dattier du désert (Balanites aegyptiaca L.) -Valorisation des constituants de la graine de neem par bioraffinage. Tese (Doutorado Sciences des Agroressources) - Université de Toulouse.

El-Khatib, E. M., Ali, N. F., \& El-Mohamedy, R. S. R. (2017). Influence of Neen oil pretreatment on the dyeing and antimicrobial properties of wool and silk fibers with some natural dyes. Arabian Journal of Chemistry.

Espich, C. (2014). Avaliação microbiológica da eficácia da limpeza de equipamentos de indústria produtora de candies, localizada na cidade de Lajeado - RS. Trabalho de Conclusão de Curso (Graduação em Química Industrial) - Centro Universitário Univates, Univates, Lajeado.

Evbuomwan, B. O., Felix-Achor, I., \& Opute, C. C. (2015). Extraction and Characterization of Oil from Neem seeds, leaves and barks. European International Journal of Science and Technology, 4(7), 1-7.

Faye, M. (2010). Nouveau procede de fractionnement de la graine de neem (Azadirachta indica A.jussi) senegalais: production d'un bio-pesticide d'huile et de tourteau. Tese (Doutorado Sciences des Agroressources) - Université de Toulouse, Toulouse, 2010.

Fernandes, S. R. R. (2014). Doseamento da Azadiractina e avaliação da atividade antimicrobiana em produtos contendo óleo de Neem. Dissertação (Mestrado em Bioquímica em Saúde) Escola Superior de Tecnologia da Saúde do Porto - ESTSP, Porto.

Fuentes, D. R., \& Silva, R. F. (2013). Efecto biocida in vitro del extracto foliar de Azadirachta indica en Staphylococcus sp y Pseudomonas sp. Salus, 17(3), 34-41.

Glisic, S. B., Ristic, M., \& Skala, D. U. (2011). The combined extraction of sage (Salvia officinalis L.): ultrasound followed by supercritical CO 2 extraction. Ultrasonics Sonochemistry, 18, 318-326.

Gomes, R. U. (2019). Produção do óleo da semente de Nim (Azadirachta indica) na mesorregião do sertão alagoano: efeito da secagem e do método de extração. 2019. Dissertação (Mestrado em Engenharia Química) - Universidade Federal de Alagoas, Alagoas.

Gosh, V., Sugumar, S., Mukherjee, A., \& Chandrasekaran, N. (2016). Neem (Azadirachta indica) Oils. Essential Oils in Food Preservation, Flavor and Safety, 593-599.

Hashemi, S. M. B., Khaneghah, A. M., Koubaa, M., Barba, F. J., Abedi, E., Niakousari, M., \& Tavakoli, J. (2018). Extraction of essential oil of Aloysia citriodora Palau leaves using continuous and pulsed ultrasound: kinetics, antioxidant activity and antimicrobial properties. Process Biochemistry, 65, 197-204.

Hari, D. K. P. S. Synthesis, Characterization and Antibacterial effect of Neem Oil Nanoemulsion. Research J. Pharm. and Tech., $12,4400-4404$.

Hernández-Hernández, E., Paredes-Cuevas, B., Castillo-Hernández, M., García-Barrientos, R., Guerrero-Legarreta, I., \& Minor-Perez, H. (2011). Actividad antimicrobiana de extractos etanólicos de orégano, romero y neem en medio sólido (gel de TSA) sobre microorganismos de importancia en alimentos. In: XIV CONGRESSO NACIONAL DE BIOTECNOLOGÍA Y BIOINGENIERÍA, 14, 2011, Querétaro. Querétaro, QUE: Consejo Nacional de Ciencia y Tecnología.

Herzi, N., Bouajila, J., Camy, S., Romdhane, M., \& Condoret, J. S. (2013). Comparison of different methods for extraction from Tetraclinis articulata: Yield, chemical composition and antioxidant activity. Food Chemistry, 141(4), 3537-3545.

Hillen, T., Schwan-Estrada, K. R. F., Mesquini, R. M., Cruz, M. E. S., Stangarlin, J. R., \& Nozaki, M. (2012). Atividade antimicrobiana de óleos essenciais no controle de alguns fitopatógenos fúngicos in vitro e no tratamento de sementes. Rev. Bras. Pl. Med., Botucatu, 14(3), 439-445.

Hummel, H. E., Hein, D. F., \& Schmutterer, H. (2012). The coming of age of azadirachtins and related tetranortriterpenoids. JBiopest, 5 , 82-87.

Jamshidi, R., Afzali, Z, \& Afzali, D. (2009). Chemical Composition of Hydrodistillation Essential Oil of Rosemary in Different Origins in Iran and Comparison with Other Countries. American-Eurasian J. Agric. \& Environ. Sci., 5 (1): 78-81.

Koona, S., \& Budida, S. (2011). Antibacterial Potential of the Extracts of the Leaves of Azadirachta indica Linn. Not. Sci. Biol., 3, 65-69.

Kumar, P. S., Mishra, D., Ghosh, G., \& Panda, C. S. (2010). Biological action and medicinal properties of various constituent of Azadirachta indica (Meliaceae): an overview. Annals of Biological Research, 1(3), 24-34.

Kumar, U. S. U., Abdulmadjid, S. N., Olaiya, N. G., Amirul, A. A., Rizal, S., Rahman, A. A., \& Khalil, H. P. S. A. (2020). Extracted Compounds from Neem Leaves as Antimicrobial Agent on the Physico-ChemicalProperties of Seaweed-Based Biopolymer Films. Polymers, 12(1119), 2-17.

Kurekci, C., Padmanabha, J., Bishop-Hurley, S. L., Hassan, E., Jassim, R. A. M. A., \& McSweeney, C. S. (2013). Antimicrobial activity of essential oils and five terpenoid compounds against Campylobacter jejuni in pure and mixed culture experiments. International Journal of Food Microbiology, (166), $450-457$. 
Machado, P. P., Vieira, G. H. C., \& Machado, R. A. (2015). Uso da própolis e óleo denim no controle dosfungos Lasiodiplodiatheobromae e Colletotrichum gloesporioides: principais patógenos que acometem os frutos da manga. Revista de Agricultura Neotropical, 2(4), 31-37.

Martinez, S. S. (Ed.) (2011). O nim-Azadirachta indica - natureza, usos múltiplos, produção. 2.ed. Londrina - PR: IAPAR.

Mejri, J., Abdelkarin, A., Mejri, M., \& Abderraba, M. (2018). Emerging extraction processes of essential oils: A review. Asian Journal of Green Chemistry, $171-280$.

Nde, D. B., Boldor, D., \& Astete, C. (2015). Optimization of microwave assisted extraction para-meters of neem (Azadirachta indica A. Juss) oil using the Doehlert's experimental design. Industrial Crops and Products, 65, 233-240.

Ofori-Boateng, C., Teong, L. K., \& Jitkang, L. (2012). Comparative exergy analyses of Ja-tropha curcasoil extraction methods: Solvent and mechanical extraction processes. Energy Conversion and Management, 55, 164-171.

Ogbuewu, I. P., Odoemenam, V. U., Obikaonu, H. O., Opara, M. N., Emenalom, O. O., Uchegbu, M. C., \& Iloeje, M. U. (2011). The growing importance of neem (Azadiractha indica A. Juss) in agriculture, industry, medicine and environment: a review. Research Journal of Medicinal Plant, 5(3), 230-245.

OMS - Organização Mundial da Saúde. (2021). World Health Organization. Recuperado de www.who.int/.

Oliveira, P. C. C. (2013). Remoção biológica de compostos BTEX (benzeno, tolueno, etilbenzeno e xilenos) e nutrientes de águas contaminadas por gasolina por uso de reator contínuo de leito fixo inoculado com fungos. (Dissertação de Mestrado), Instituto Federal de Educação, Ciência e Tecnologia do Ceará, Fortaleza.

OPAS - Organização Panamericana de Saúde. (2021). PAHO. http://www.paho.org

Oyeskanmi, A. A., Kumar, U. S. U., Khalil, H. P. S. A., Olaiya, N. G., Amirul, A. A., Rahman, A. A., \& Rizal, S. (2021). Functional Properties of Antimicrobial Neem Leaves Extract Based Macroalgae Biofilms for Potential Use as Active Dry Packaging Applications. Polymers, 13 (1664), $2-22$.

Paes, J. B., Souza, A. D., Lima, C. R., \& Santana, G. M. (2015). Rendimento e Características Físicas dos Óleos de Nim (Azadirachta indica) e Mamona (Ricinus communis). Floresta e Ambiente, 22(1),134-139.

Palanappian, K., Holley, R. A. (2010). Use of natural antimicrobials to increase antibiotic susceptibility of drug resistant bacteria. Int. J. Food Microbiol., (140). 164-168

Parckert, E. D. T., Bittar, I. R. S., Almeida, G. M., \& Souza, A. C. (2017). Isotermas de adsorção de folhas de Nim (azadirachta indica) desidratadas. In: Encontro De Desenvolvimento De Processos Agroindustriais, 1., Uberaba, Anais... Uberaba, SP: Uniude.

Picó, Y. Ultrasound-assisted extraction for food and environmental samples. Trends in Analytical Chemistry, 43, 84-99.

Pingret, D., Fabiano-Tixier, A. S., \& Chemat, F. (2013). Ultrasound-assisted extraction, in: Rostagno, M. A., Prado, J. M. (EDS.), Natural Product Extraction: Principles and Applications. The Royal Society of Chemistry, 89-112.

Porto, C. D.A., Porretto, E., \& Decorti, D. (2013). Comparison of ultrasound-assisted extraction with conventional extraction methods of oil and polyphenolsfrom grape (Vitis vinifera L.) seeds. Ultrasonics Sonochemistry, 20, 1076-1080.

Quelemes, P. V., Perfeito, M. L. G., Guimarães, M. A., Santos, R. C., Lima, D. F., Nascimento, C., \& Leite, J. R. S. A. (2015). Effect of neem (Azadirachta indica A. Juss) leaf extract on resistant Staphylococcus aureus biofilm formation and Schistosoma mansoni worms. Journal of Ethnopharmacology. 175(1), 287-294.

Ramalho, H. F., \& Suarez, P. A. Z. (2012). A Química dos Óleos e Gorduras e seus Processos de Extração e Refino. Revista Virtual de Química, 5(1), 2-15. ISSN 1984-6835.

Rault, J. S., \& Karuppayil, S. M. (2014). A status review on the medicinal properties of essential oils. Industrial Crops and Products, 62, 250-264.

Rostagno, M. A., \& Prado, J. M. (2013). Natural product extraction: principles and applications. Royal Society of Chemistry, 500.

Sá, C. S. A., Ladchumananandasivam, R., Rossi, C.G. F. T., Silva, R. K., Camboim, W. S., Zille, A., \& Silva, K. K. O. S. (2021). Characterization of a natural surfactant from an essential oil from neem (Azadirachta indica A. Juss) for textile industry applications. Textile Research Journal, O(0), 1-8.

Santos, R. A., Andreão, A., Andreão, P. S. S., \& Nascimento, I. A. (2011). Caracterização fitoquímica do óleo essencial de Costus spiralis. Sociedade Brasileira de Química, (34).

Serrone, P. D., \& Nicoletti, M. (2013). Antimicrobial Activity of a Neem Cake Extract in a Broth Model Meat System. Int. J. Environ. Res. Public Health, 3282-3295.

Silva, M. G. F. (2011). Atividade antioxidante e antimicrobiana in vitrode óleos essenciais e extratos hidroalcóolicos de manjerona (Origanum majoranaL.) e manjericão (Ocimum basilicumL.). Trabalho de Conclusão de Curso -Curso Superior de Química - Bacharelado em Química Industrial/Licenciatura em Química, Universidade Tecnológica Federal do Paraná. Pato Branco.

Silveira, J. C., Busato, N., Costa, A., \& Costa Junior, E. (2012). Levantamento e análise de métodos de extração de óleos essenciais. Enciclopédia Biosfera, $8(15)$.

Siqueira, G. (2021). Teor de sólidos e teor de umidade. Linkedin. Recuperado de https://pt.linkedin.com/pulse/teor-de-s\%C3\%B3lidos-umidade-o-que$\%$ C3\%A9-qual-import\%C3\%A2ncia-quais-siqueira

Solino, A. J. S., Neto, S. E. A., Silva, A. N., \& Ribeiro, A. M. A. S. (2021). Severidade da antracnose e qualidade dos frutos de maracuja-amarelo tratados com produtos naturais em pós-colheita. Rev. Bras. Frutic., 34(1), 057-066. 
Research, Society and Development, v. 10, n. 15, e507101523154, 2021

(CC BY 4.0) | ISSN 2525-3409 | DOI: http://dx.doi.org/10.33448/rsd-v10i15.23154

Soria, A. C., \& Villamiel, M. (2010). Effect of ultrasound on the technological properties and bioactivity of food: a review. Trends in Food Science \& Technology, 21, 323-331.

Suryawanshi, J. A. S. (2011). Neem - natural contraceptive for male and female - an overview. Int. J. Biomol. \& Biomed, 1(2), 1-6.

Susmitha, S., Vidyamol, K. K., Ranganayaki, P., \& Vijayarghavan, R. (2013). Phytochemical Extraction and Antimicrobial Properties of Azadirachta indica (Neem). Global J. Pharmacol., 7(3), 316-320.

Tesfaye, B., Tefera, T., Misikir, O., \& Tsegaye, G. (2018). Extraction and comparison of essential oil from Neem seed by using Soxhlet extraction and simple distillation methods. International Journal of Engineering Technologies and Management Research, 5(9), 74-81.

Thyiagu, T. T., \& Rajeswari, N. (2019). Effect of nanosilica and neem tree oil on antimicrobial, thermal, mechanical and electrical insulate of biodegradable composite film. Mater. Res. Express, 6(9), 1-11.

Tiwari, B. K. (2015). Ultrasound: A clean, green extraction technology. Trends in Analytical Chemistry, 71, $100-109$.

Velickovic, D. T., Milenovic, D. M., Ristic, M. S., \& Veljkovic, V. B. (2010). Ultrasonic extraction of waste solid residues from Salviasp. Essential oil hydrodistillation. Central European Journal of Chemistry, 8, 87-95.

Ventorim, K. (2020). Neem: planta ainda pouco conhecida no Brasil pode proteger o rebanho. iAgro. Recuperado de http://www.iagro.ms.gov.br/neem-plantaainda-pouco-conhecida-no-brasil-pode-proteger-o-rebanho/

Vinatoru, M., Mason, T. J., \& Calinescu, I. (2017). Ultrasonically assisted extraction (UAE) and microwave assisted extraction (MAE) of functional compounds from plant materials. Trends in Analytical Chemistry, 97, 159-178.

Yacila, R. A., Álvarez, F. C., Alarcón, S. G., Flores, A. G., Atarama, M. I., \& Cruz, R. L. (2015). Diseño de la línea de produccíon de tres bioinsecticidas a base de la semilla, cáscara y residuos del grano em la extraccíon del aceite del árbol Azadirachta indica. Pirhua. https://pirhua.udep.edu.pe/bitstream/handle/11042/2335/9._PYT_Informe_Final_Bioinsecticidas.pdf?sequence=1\&isAllowed=y

Zhong, K.; \& Wang, Q. (2010). Optimization of ultrasonic extraction of polysaccharides from dried longan pulp using response surface methodology. Carbohydrate Polymers, 80, 19-25. 